\title{
TREINAMENTO DE HABILIDADES SOCIAIS EM UNIVERSITÁRIOS: UM ESTUDO ACERCA DAS VARIÁVEIS ESTRESSE E HABILIDADES SOCIAIS
}

\section{Training of Social Skills in university students: a clipping study about the variables stress and social skills}

\author{
Thaís Cristina Gutstein Nazar - UNIPAR/UFPR/Brasil \\ Amanda Caroline Pering - UNIPAR /Brasil \\ Déborah Alana Girotto - UNIPAR /Brasil \\ Tatiane Kucmanski - UNIPAR /Brasil
}

\begin{abstract}
RESUMO: O presente trabalho trata-se de um estudo sobre a realização de um programa intitulado Treinamento de Habilidades Sociais (THS), o qual buscou, através de seus encontros, avaliar seus efeitos no repertório de Habilidades Sociais (HS) e no nível de estresse de estudantes universitários. O treinamento se deu em cinco etapas sendo elas: período de inscrições, entrevista de triagem, pré-teste, aplicação do programa e pós-teste. A aplicação do programa foi composta por 10 encontros grupais, e para a testagem foram utilizados instrumentos como o Inventário de Habilidades Sociais (IHS) e Inventário de Sintomas de Stress de Lipp (ISSL). Os resultados obtidos anteriores ao THS, as observações, e relatos dos participantes bem como a aplicação dos testes (IHS e ISSL), evidenciam dificuldades dos participantes relacionadas às HS e o estresse, mas através dos encontros, os repertórios comportamentais mostraram-se aprimorados.
\end{abstract}

Palavras-chave: Universitários, Habilidades Sociais, Estresse

ABSTRACT: The present work is a study about the accomplishment of a program called Social Skills Training (SST), which sought, through its meetings, to evaluate its effects on the Social Skills (SS) repertoire and on the stress level of university students. The training took place in five stages: registration period, screening interview, pre-test, program application and post-test. The application of the program consisted of 10 group meetings, and for testing were used instruments such as the Social Skills Inventory (SSI) and Lipp Stress Symptom Inventory (LSSI). The results obtained prior to the THS, the participants 'observations and reports, as well as the application of the tests (SSI and LSSI), evidenced the participants' difficulties related to SS and stress, but through the meetings, the behavioral repertoires were improved.

Keywords: College students, Social Skills, Stress 
Treinamento de habilidades sociais em universitários: um estudo acerca das variáveis estresse e habilidades sociais

\section{INTRODUÇÃO}

Indubitavelmente, habilidades e competências sociais são apreendidas e consequentemente aperfeiçoadas ao longo da vida do indivíduo, considerando-se este como pertencente a diferentes grupos sociais (DEL PRETTE; DEL PRETTE, 2017). A família é o primeiro contato deste com o mundo, é ela quem pune ou reforça os primeiros comportamentos, fator que será continuado em sua inserção a grupos subsequentes como a escola e outros grupos sociais de interesse (ROCHA, 2012). Ainda segundo a autora, é inserido nestes contextos que há maior possibilidades de adquirir-se - por meios de convívio e aprendizagem - maior repertório habilidoso.

Segundo Borba (2018), se faz de extrema importância o desenvolvimento das Habilidades Sociais (HS) para que hajam interações sociais bem sucedidas, porém, estas só podem ser assimiladas através da interação com outros indivíduos. A autora ainda cita, que é desde o primeiro contato com os pais, que a criança absorve e assimila várias habilidades, as quais são necessárias para o convívio físico e social. Portanto, de acordo com Borba (2018, p. 25) "se a criança desenvolver um amplo repertório de HS terá maior probabilidade de estabelecer relações sociais saudáveis e com menor risco de rejeição por seus pares". Para Gavasso, Fernandes e Andrade (2016), esse desenvolvimento das HS na infância, ainda pode compor um fator de proteção antagonista a casos de dificuldades de aprendizagem e também de alguns comportamentos considerados antissociais.

Bolsoni-Silva e Carrara (2010, p. 330) contemplam que as HS "podem ser conceituadas como conjunto de comportamentos emitidos diante das demandas de uma situação interpessoal, desde que maximizem os ganhos e reduzam as perdas para as interações sociais". Ainda sobre as HS, Del Prette e Del Prette (2017, p. 20) vão identificá-las como "classes sociais que somente podem ser classificadas como tais na medida em que contribuem para a competência social”. Moretto (2017) identifica essas classes, em consonância com Del Prette e Del Prette (2001), como habilidades pertinentes à comunicação, civilidade, enfrentamento, empatia, trabalho e expressão de sentimentos positivos. Em confluência de pensamentos entre os autores supracitados, acredita-se que estas habilidades são essenciais no desempenho de relações interpessoais, em primazia no decorrer da vida acadêmica de universitários; público sobre o qual discutir-se-á no presente artigo.

Educação, Psicologia e Interfaces, Volume 4, Número 1, p. 190-204, Janeiro/Março, 2020.

ISSN: 2594-5343. DOI: https://doi.org/10.37444/issn-2594-5343.v4i1.210 
Olaz et al (2017), concomitante aos pensamentos de Monteiro, Freitas e Ribeiro (2007), tratam o ingresso à vida acadêmica como um momento de importante transição para o indivíduo que o faz, devido as novas perspectivas de vida que se mostram longe de casa e/ou em contato com novas pessoas, sendo também, e por conta disso, um ambiente de intensa cobrança, gerador de tensões e também do famigerado estresse. $\mathrm{Na}$ expressão de Monteiro, Freitas e Ribeiro (2007, p. 67),

[...] o ambiente que contribuiria na edificação do conhecimento e ser a base para as suas experiências de formação profissional se torna, por vezes, o desencadeador de distúrbios patológicos, quando ocorre uma exacerbação da problemática do estresse acadêmico nos estudantes.

Compreende-se, dessa forma, que a exacerbação de cobranças por parte do núcleo familiar, institucional e também social, causa afetabilidade direta na vida do sujeito, inferindo em seus modos de vida, podendo desencadear uso e abuso de substâncias, além de baixa no desempenho acadêmico, e alavancar problemas de interação interpessoal (OLAZ et al. 2017). Para tanto, e pensando-se a partir de uma perspectiva protetiva, o programa de Treinamento de Habilidades Sociais (THS), além de potencializar o repertório comportamental, possibilita o desenvolvimento de relações interpessoais mais efetivas, gerando maior satisfação e sensação de bem-estar, uma vez que este (THS), distingue-se por ser uma das técnicas de grande potencial efetivo na melhora da qualidade de vida e de relacionamento (CABALLO, 2016), e reduz déficits do desenvolvimento comuns na adolescência, a exemplo da ansiedade social (OLAZ et al. 2017).

Estudos brasileiros acerca das HS, identificam que o treinamento de habilidades encontra-se ligado com mais frequência às populações universitárias, seguindo-se de figuras parentais e crianças (BOLSONI-SILVA; CARRARA, 2010). Em análise bibliográfica, Moretto (2017) constata que de modo generalizado, estes estudos com o público acadêmico apresentam um padrão referente ao método de avaliação e a constância do programa, encontrando uma estimativa de encontros interventivos (10 a 22), e uma regularidade na aplicação do Inventário de Habilidades Sociais (DEL PRETTE; DEL PRETTE, 2001) como forma de avaliar variáveis, com exceção do estudo produzido por Lima e Soares (2016, apud Moretto, 2017), onde foram utilizados os próprios relatos dos participantes. 
Treinamento de habilidades sociais em universitários: um estudo acerca das variáveis estresse e habilidades sociais

Para Rocha (2012), os universitários são apresentados a várias situações, que muitas vezes, são consideradas dificuldades sociais, por exemplo: dificuldade de falar em público, medo de se relacionar com outras pessoas, temor de não ser aprovado pelos outros indivíduos, dificuldade na expressão de sentimentos, de opinar, recusar ou discordar de algo, etc. Para ela, "essas situações podem ser enfrentadas com ansiedade social para os indivíduos, principalmente para aqueles que apresentam déficits em habilidades sociais" (ROCHA, 2012, p. 22).

Strahan (2003) apurou a compatibilidade de ansiedade social, habilidades sociais e desempenho acadêmico de universitários. "Participaram do estudo 55 universitários ansiosos socialmente e 198 universitários não-clínicos. Os resultados indicaram que os estudantes com ansiedade social apresentavam dificuldades significativamente maiores na habilidade verbal de expressar-se socialmente, na interpretação adequada da comunicação verbal dos outros e na habilidade de apresentar-se e desempenhar papéis" (ROCHA, 2012, p. 22). Diante disso, averigua-se a importância das HS para os universitários, pois as “dificuldades interpessoais estão associadas a sensações de intenso desconforto e frequente tentativa de esquiva de situações sociais, o que constitui fator de risco para a fobia social e isolamento" (BOAS; SILVEIRA; BOLSONI, 2005, p. 324).

Em estudo anterior Furtado, Falcone e Clark (2003), identificaram uma relação pertinente entre habilidade social e estresse, demonstrando que um baixo indicativo da primeira, pode acarretar em um aumento da segunda variável. De acordo com Chaves et al (2016), o fator estresse configura-se como "uma reação de adaptação do organismo diante de um estímulo externo proveniente do meio em que se está inserido ou uma resposta a um estímulo interno, relacionado a fatores psíquicos e/ou fisiológicos" (CHAVES et al. 2016, p. 21). Baseando-se na premissa do ambiente acadêmico como gerador e por vezes demasiado potencializador de estresse em universitários, contribuir para que este público seja mais habilidoso socialmente torna-se um dos objetivos primordiais ao se pensar na construção do THS.

\section{MATERIAL E MÉTODO}

\subsection{Estudo realizado}


O estudo realizado foi de caráter quantitativo, pois buscou, através da aplicação dos instrumentos, medir o nível de estresse e de habilidades sociais dos participantes, gerando resultados no pré e pós-teste, que puderam ser analisados e comparados, sendo expostos em forma de tabela, assim, avaliando o efeito do programa sob os participantes. Entretanto, também pode ser considerada qualitativa, pois, houve momentos em que puderam expor suas subjetividades, suas opiniões, além de fazerem um feedback no final do treinamento, onde expuseram suas satisfações e insatisfações diante dos encontros realizados, além de possíveis mudanças no THS. Possuindo como objeto de estudo pessoas, para que a presente pesquisa pudesse transcorrer, esta passou por submissão, análise e aprovação do Comitê de Ética em Pesquisa da UNIPAR conforme o Parecer: 3.146.331 e $\mathrm{n}^{\circ}$ CAAE: 93703418.4.0000.0109 e se pauta nos princípios e normas estabelecidas pela Resolução 466/2012.

\subsection{Participantes}

O estudo teve como público universitários, contando com 10 participantes de instituições públicas e privadas, com inserção em cursos diversos, mas havendo uma predominância de 60\% (n=6) dos participantes cursando Psicologia (Tabela 1.1). Os participantes inscreveram-se por meio de questionário eletrônico e, posteriormente, passaram por entrevista de triagem, onde foi necessária a assinatura do Termo de Consentimento Livre e Esclarecido (TCLE) para a continuidade do programa.

Educação, Psicologia e Interfaces, Volume 4, Número 1, p. 190-204, Janeiro/Março, 2020.

ISSN: 2594-5343. DOI: https://doi.org/10.37444/issn-2594-5343.v4i1.210 
Treinamento de habilidades sociais em universitários: um estudo acerca das variáveis estresse e habilidades sociais

Tabela 1.1 - Tabela de amostra de participantes

\begin{tabular}{lcc}
\hline Participantes & Instituição & Curso \\
\hline P1 & Privada & Ciências Contábeis \\
P2 & Privada & Psicologia \\
P3 & Pública & Engenharia Ambiental \\
P4 & Privada & Farmácia \\
P5 & Privada & Psicologia \\
P6 & Privada & Psicologia \\
P7 & Privada & Psicologia \\
P8 & Privada & Psicologia \\
P9 & Privada & Psicologia \\
P10 & Pública & Engenharia Ambiental \\
\hline
\end{tabular}

Tabela 1.1

\subsection{Instrumentos}

Como método avaliativo, foram utilizados o Inventário de Habilidades Sociais (IHS-DEL PRETTE; DEL PRETTE, 2001) e o Inventário de Sintomas de Stress de Lipp (ISSL - LIPP, 2005).

Inventário de Habilidades Sociais -IHS (DEL PRETTE; DEL PRETTE, 2001), composto por 38 itens (devendo ser respondidos com: nunca ou raramente - 0 ; com pouca frequência - 1; com regular frequência - 2; muito frequentemente - 3; sempre ou quase sempre - 4). Os itens se dividem em fatores: enfrentamento com risco (F1), autoafirmação na expressão de afeto positivo (F2), conversação e desenvoltura social (F3), autoexposição a desconhecidos ou a situações novas (F4) autocontrole da agressividade em situações aversivas (F5).

Inventário de Sintomas de Stress de Lipp ISSL (LIPP, 2005), baseado no modelo quadrifásico de Lipp, contendo 3 quadros que fazem referência ao estresse e suas fases, sendo estas: a) Fase de Alerta: constituindo-se com a primeira delas e a fase positiva do estresse, onde uma sensação plena é experienciada; b) Fase de Resistência: é a segunda fase do estresse, e o momento em que o organismo lidar com fatores estressores que surgem, tentando manter o equilíbrio; c) Fase de Quase-Exaustão: fase onde as barreiras 
começam a ruir, perdendo a capacidade de lidar com esses estressores e manter o equilíbrio necessário para evitar patologias; d)Fase de Exaustão: considerada a última e mais preocupante fase do estresse, em que o surgimento de patologia como a depressão são iminentes, atingindo pontos de maior vulnerabilidade do indivíduo (ROSSETTI et al. 2008).

De modo geral, o instrumento apresenta 37 itens de caráter somático e 19 de caráter psicológico. A aplicação do instrumento permite a identificação da existência ou não de estresse, identificando também as fases de estresse em que cada participante se encontra, além de apontar "a área de maior vulnerabilidade, onde o stress se manifesta na pessoa avaliada" (LIPP, 2017, p. 52), tornando possível, tanto a identificação do estresse, como da sintomatologia física e/ou psicológica ligada ao estresse.

\subsection{Processo Interventivo análise de dados}

O THS foi composto por 10 encontros semanais, incluindo Pré-Teste e Pós-Teste, ambos realizados no Centro de Psicologia Aplicada da Universidade Paranaense (UNIPAR), com duração média de 2 horas cada.

Para a realização do Pré e Pós-Testes foi utilizada Sala de Avaliação apropriada, e para a aplicação das intervenções em si, foi utilizado o espaço de Sala de Grupo, ambas localizadas no Centro de Psicologia Aplicada da UNIPAR.

Os encontros tiveram como proposta a abordagem da 1) autoexposição a desconhecidos e situações novas; 2) conversação e desenvoltura social; 3) autocontrole da agressividade: nem agressivo, nem passivo, assertivo; 4) enfrentamento; 5) autoafirmação na expressão de sentimento positivo; 6) enfrentamento e autoafirmação com risco; $7^{\circ}$ Enfrentamento e autoafirmação com risco; $8^{\circ}$ Encerramento e Pós-teste.

Após a coleta de dados através dos instrumentos utilizados para o processo de avaliação do THS, utilizou-se como base de análise dos dados o software SPSS Statistics, onde foram analisados o ISSL e o IHS, buscando identificar as diferenças que a intervenção possa ter gerado nesses dois âmbitos, tanto no repertório de habilidades sociais, quanto no nível de estresse dos participantes.

\section{RESULTADOS E DISCUSSÃO}


Treinamento de habilidades sociais em universitários: um estudo acerca das variáveis estresse e habilidades sociais

Constatou-se, a partir das observações, relatos e aplicação dos testes, que os participantes possuíam dificuldades relacionadas às HS e estresse, porém, buscavam participar das atividades e consequentemente, aprimorar seus repertórios comportamentais.

O Gráfico 1 acerca da Identificação de Estresse e Sintomas Físicos e Psicológicos em Universitários revela os resultados obtidos a partir do ISSL (Lipp, 2005) no pré e pósteste, onde foram identificados que no pré-teste, $80 \%(\mathrm{n}=8)$ dos participantes possuíam estresse, número que reduziu para $50 \%(n=4)$ no pós-teste. No mesmo gráfico é possível observar que relativo a identificação de sintomas, no pós-teste, $20 \%(\mathrm{n}=2)$ possuíam sintomas físicos, fator com significativo aumento de $37,5 \%(n=3)$ no pós-teste. E relativo aos sintomas psicológicos, no pré-teste foram identificados $80 \%(\mathrm{n}=8)$ de participantes com esse tipo de sintoma, diminuindo para $75 \%(n=6)$ no pós-teste.

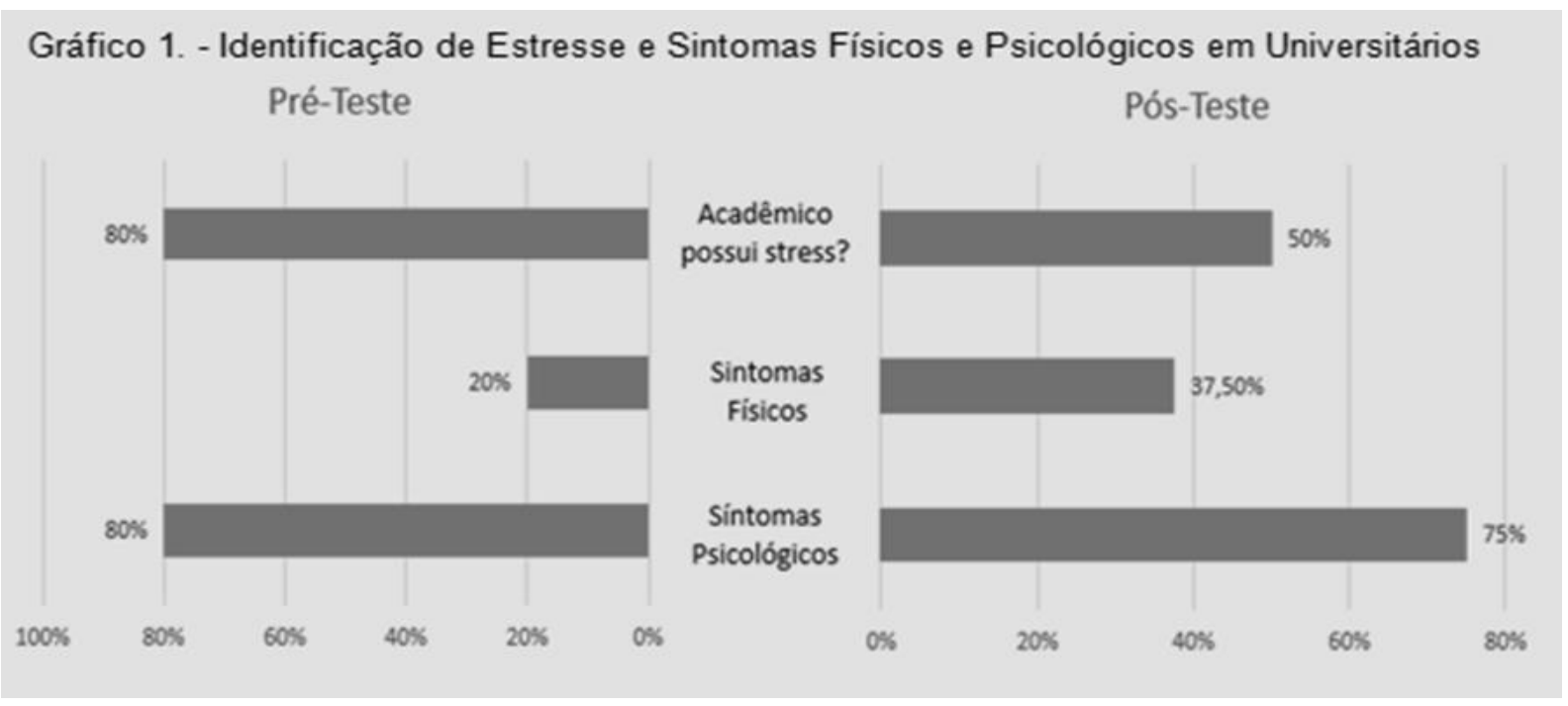

Acerca das fases do estresse, a Tabela 1.2 demonstra a incidência de universitários nas respectivas fases antes e depois do processo interventivo. A exemplo da Fase de Alerta, a primeira das quatro fases, identificou-se que nenhum participante estava inciso nesta fase, tanto no pré quanto no pós-teste, o resultado permaneceu nulo. Relativo a Fase de Resistência, identificou-se que $20 \%$ ( $n=2$ ) estavam nesta fase no pré-teste, número que aumentou no pós-teste com identificação $37,5 \%(n=3)$ de participantes. Pertinente a terceira fase, constatou-se que 50\% (n=5) dos participantes estavam em fase de quaseexaustão no pré-teste, reduzindo significativamente no pós-teste para $12,5 \%(n=1)$ de 
participantes. Referente a Fase de Exaustão, observou-se que 10\% (n=1) dos participantes estavam nessa fase no pré-teste, número que reduziu para zero no pós-teste.

Tabela 1.2 - Fases do Estresse

\begin{tabular}{|c|c|c|c|c|}
\hline & \multicolumn{2}{|c|}{ PRÉ-TESTE } & \multicolumn{2}{|c|}{ PÓS-TESTE } \\
\hline & Sim & Não & Sim & Não \\
\hline Fase de Alerta & - & $100 \%$ & - & $100 \%$ \\
\hline Fase de Resistência & $20 \%$ & $80 \%$ & $37,50 \%$ & $62,50 \%$ \\
\hline $\begin{array}{c}\text { Fase de Quase } \\
\text { Exaustão }\end{array}$ & $50 \%$ & $50 \%$ & $12,50 \%$ & $87,50 \%$ \\
\hline Fase de Exaustão & $10 \%$ & $90 \%$ & - & $100 \%$ \\
\hline Total de Participantes & \multicolumn{2}{|c|}{$100 \%$} & \multicolumn{2}{|c|}{$80 \%$} \\
\hline
\end{tabular}

A Tabela 1.3 acerca da Identificação de Habilidades Sociais em Universitários revela os resultados obtidos a partir do IHS (DEL PRETTE; DEL PRETTE, 2001) no pré e pós-teste. No pré-teste o escore total dos participantes da pesquisa foi 76,75 pontos em HS, comparando com o pós-teste no qual o resultado foi 86,75 pontos este estudo apresentou um avanço de 10 pontos nos escores totais. Os itens se dividem em fatores: enfrentamento com risco (F1), auto-afirmação na expressão de afeto positivo (F2), conversação e desenvoltura social (F3), autoexposição a desconhecidos ou a situações novas (F4) autocontrole da agressividade em situações aversivas (F5). Considerando estes escores fatoriais, os participantes em relação do pré-teste com o pós-teste avançaram 0,64 pontos em F1, em F2 variaram subindo 0,07, em F3 variaram 0,21, em F4 variaram 0,06, e em F5 variaram 0,20. 
Treinamento de habilidades sociais em universitários: um estudo acerca das variáveis estresse e habilidades sociais

Tabela 1.3 - Identificação de Habilidades Sociais em Universitários

\begin{tabular}{|c|c|c|c|c|c|c|c|c|c|c|c|c|}
\hline & $F 1 P$ & $F 1 P 0$ & $F 2 P$ & $F 2 P 0$ & $F 3 P$ & $F 3 P O$ & $F 4 P$ & $F 4 P O$ & $F 5 P$ & $F 5 P O$ & ETP & ETPO \\
\hline$P 1$ & 0,55 & 2 & 2,29 & 2,57 & 2,14 & 1,43 & 1 & 1 & 3,33 & 3 & 51 & 63 \\
\hline$P 2$ & 1,73 & 1,73 & 3,57 & 3 & 3 & 3,29 & 3,25 & 2 & 3,67 & 3 & 89 & 80 \\
\hline$P 3$ & & & & & & & & & & & & \\
\hline$P 4$ & 1,55 & 2,36 & 3 & 3,43 & 1,43 & 2,57 & 2,5 & 2,75 & 2,33 & 2 & 65 & 85 \\
\hline$P 5$ & 3 & 3,18 & 3,71 & 3,43 & 2,71 & 2,57 & 3 & 3,75 & 3,33 & 3,67 & 100 & 103 \\
\hline$P 5$ & 1,27 & 1,27 & 1,71 & 3,14 & 1,71 & 1,71 & 2 & 2 & 2,67 & 3,67 & 54 & 67 \\
\hline$P 7$ & 3,27 & 2,82 & 3,14 & 2,71 & 3,14 & 3 & 4 & 3,5 & 3 & 3,33 & 105 & 95 \\
\hline$P 8$ & 2,09 & 3,18 & 4 & 3,86 & 2,71 & 3,29 & 2 & 2,25 & 3,33 & 3,33 & 88 & 104 \\
\hline$P 9$ & 1,27 & 3,36 & 3,71 & 3,57 & 1,43 & 2,14 & 1 & 2 & 2,57 & 4 & 62 & 97 \\
\hline$P 10$ & & & & & & & & & & & \\
\hline
\end{tabular}

\begin{tabular}{|c|c|c|c|c|c|c|c|c|c|c|c|}
\hline $\begin{array}{c}\text { Médio F1 totol } \\
\text { pré-teste: }\end{array}$ & 1,84125 & $\begin{array}{l}\text { Médio f2 } \\
\text { totol pré- } \\
\text { teste: }\end{array}$ & 3,14125 & $\begin{array}{l}\text { Médio Fs } \\
\text { total pré. } \\
\text { teste: }\end{array}$ & 2,28375 & $\begin{array}{l}\text { Medilo Fi } \\
\text { totol pré- } \\
\text { teste: }\end{array}$ & 2,34373 & $\begin{array}{c}\text { Média F5 } \\
\text { total pré- } \\
\text { teste: }\end{array}$ & 3,04125 & $\begin{array}{c}\text { Média } \\
\text { excore total } \\
\text { préteste: }\end{array}$ & 76,75 \\
\hline $\begin{array}{c}\text { Médio fi totol } \\
\text { pós-teste: }\end{array}$ & 2,4875 & $\begin{array}{l}\text { Medio Fi2 } \\
\text { total pós. } \\
\text { teste: }\end{array}$ & 3,21375 & $\begin{array}{l}\text { Medio F3 } \\
\text { total pós. } \\
\text { teste: }\end{array}$ & 2,5 & $\begin{array}{l}\text { Medio F4 } \\
\text { totol poss. } \\
\text { teste: }\end{array}$ & 2,40625 & $\begin{array}{l}\text { Medio } 15 \\
\text { totol pós- } \\
\text { teste: }\end{array}$ & 3,25 & $\begin{array}{c}\text { Média } \\
\text { escore total } \\
\text { pósteste: }\end{array}$ & 86,75 \\
\hline Diferenço: & 0,64625 & Diferença: & 0,0725 & Diferença: & 0,21625 & Differença: & 0,0625 & Diferenca: & 0,20875 & Diferença: & 10 \\
\hline
\end{tabular}

O desenvolvimento do THS mostrou-se útil, a partir da análise dos resultados obtidos, pois gerou o compartilhamento de conhecimentos e possibilitou discussões entre os participantes, o que propiciou a ampliação dos repertórios habilidosos. Soares et al (2017), trata dessas habilidades como uma forma de contribuição para que as pessoas se relacionem de modo mais positivo, isto é, as HS são de extrema importância quando se trata da forma com que os indivíduos se relacionam com o ambiente em que estão inseridos, de modo a auxiliar na diminuição de suas angústias e restrições, as quais podem ser causadas pela falta de interação ou dificuldade de interagir com os demais. Em confluência com este fato, Del Prette e Del Prette (2017, p.19) mencionam que "a aprendizagem de habilidades sociais e o aperfeiçoamento da competência social constituem processos que ocorrem "naturalmente", por meio das interações sociais cotidianas ao longo da vida".

No decorrer dos encontros, os participantes puderam criar vínculos com o grupo, além de aprender e desenvolver formas para serem mais habilidosos socialmente na relação com outras pessoas, atingindo assim, os objetivos propostos pelo programa. Compreende-se a efetividade do programa a partir da perspectiva de Del Prette e Del Prette (2017, p. 19), uma vez que "a superação de déficits de habilidades sociais e de 
problemas de competência social requer, em geral, serviços especializados no campo da Terapia e Educação", necessitando-se do aprimoramento de técnicas e procedimentos interventivos.

À partir disso resultados em relação às HS, apresentou em geral um avanço dos participantes entretanto, corroborando com a pesquisa realizada por Silva, Bonetti e Gutstein (2018) utilizando o mesmo THS, houve a diminuição dos escores em alguns fatores de participantes, o que foi entendido como resultado do desenvolvimento de autopercepção e autocrítica desenvolvida por meio do treinamento, o que levou os participantes à serem mais críticos na realização do pós teste. Também comparando com o estudo anterior foi possível perceber que o THS, se mostrou mais efetivo para público que já apresenta repertório mais elaborado de HS, já que nossos participantes tinham um repertório de HS bastante defasado o avanço foi limitado.

Partindo do pressuposto que tratam Del Prette e Del Prette (2017), é conveniente mencionar que o processo de THS ao qual foram expostos os participantes, foi preponderante nos resultados obtidos na variável estresse, uma vez evidente em análise comparativa, que houve redução de participantes com estresse ao final do programa. Relativo a suas fases, a fase de alerta manteve-se ausente em ambos os resultados, porém, houve aumento de participantes em fase de resistência, e uma redução significativa de participantes em fase de quase-exaustão e exaustão. Referente aos sintomas físicos e psicológicos, houve um acréscimo de participantes com sintomas físicos e um decréscimo de participantes com sintomas psicológicos.

Os resultados positivos obtidos, a exemplo daqueles que indicam diminuição do estresse e relativo as suas fases, corroboram com estudo realizado anteriormente e com o que trata Olaz et al (2017), sob perspectiva das HS como fatores de proteção. Por conseguinte, o THS pode ser compreendido como importante manejador do estresse e das situações que o desencadeiam. Compreende-se como de primordial importância ressaltar que em seu início o programa contava com um total de 10 participantes, número que reduziu para 8 ao final. Na identificação das fases do estresse, especificamente da última e mais importante a ser considerada por seu nível de complexidade e necessidade de observância, identificou-se que um dos participantes estava inciso na respectiva fase nos resultados observados durante o pré-teste, número que diminuiu no pós-teste para zero, coincidentemente o participante que se encontrava em fase de exaustão no pré-teste é

Educação, Psicologia e Interfaces, Volume 4, Número 1, p. 190-204, Janeiro/Março, 2020.

ISSN: 2594-5343. DOI: https://doi.org/10.37444/issn-2594-5343.v4i1.210 
Treinamento de habilidades sociais em universitários: um estudo acerca das variáveis estresse e habilidades sociais

mesmo que ausentou-se do programa, interferindo no resultado final deste tópico especificamente.

Em decorrência dos resultados negativos obtidos, que dizem respeito ao aumento de sintomas físicos e da incidência de participantes em fase de resistência, há variáveis externas não controladas que podem interferir no curso do programa, como o contexto familiar e social do indivíduo que continuam exercendo suas influências e lançando seus estigmas sobre este, ou seja, o que o indivíduo faz fora do grupo, com quem se relaciona e por quem é influenciado, por vez, não está sob controle dos terapeutas. Também sobre isso, Olaz et al. (2017, p. 184) trata de uma situação onde padrões comportamentais podem ser apreendidos, porém, podem não vir a ser desempenhados por diversos motivos, tais como "expectativas de resultados negativos ou presença de um ambiente não reforçador ou punitivo para esses comportamentos", ou seja, as habilidades adquiridas só serão evidenciadas quando houver uma situação externa que propicie isso.

Observa-se como relevante relembrar que a fase de resistência está relacionada com a necessidade orgânica do indivíduo de combater estressores e estabelecer um equilíbrio interno. Segundo Lameu, Salazar e Souza (2016), essa fase do estresse utilizase das reservas de energia do organismo como forma de estabelecer a homeostase, tendo como consequência sintomas físicos de esgotamento.

É importante ressaltar, e também como forma de contemplar as possibilidades para o surgimento dos resultados negativos supracitados, que o presente estudo passou por períodos de interferências externas limitadoras, uma vez que a finalização do estudo e a consequente aplicação do pós-teste coincidiu com a finalização do primeiro semestre letivo e com a semana de provas, fator que encontrou-se dentre um dos geradores de maior estresse entre universitários, segundo relatos dos participantes do programa. Compreende-se dessa forma, que os resultados negativos podem estar relacionados com uma fase momentâneamente conturbada envolvendo a vida acadêmica (LAMEU; SALAZA; SOUZA, 2016), e que isso possa ter causado interferências em alguns dos pontos avaliados, principalmente no que se refere aos sintomas físicos.

\section{CONSIDERAÇÕES FINAIS}

Educação, Psicologia e Interfaces, Volume 4, Número 1, p. 190-204, Janeiro/Março, 2020.

ISSN: 2594-5343. DOI: https://doi.org/10.37444/issn-2594-5343.v4i1.210 
Concluiu-se que o THS tem potência de repercussão não somente em vias pessoais, mas também no meio acadêmico e profissional, ou seja, em qualquer meio em que o indivíduo esteja inserido e necessite de interação, proporcionando a obtenção de novas experiências, as quais não seriam possíveis caso este processo de aprimoramento das HS não tivesse ocorrido.

Concernente aos métodos utilizados, considera-se que a aplicação de testes como o ISSL configurou-se como sendo de extrema importância na identificação do estresse e suas fases em universitários, tornando possível a análise e diagnóstico, além de avaliar a efetividade do programa de intervenção aplicado. As especificidades do teste foram úteis, para além da identificação das fases de estresse em que cada participante se encontra, mas também porque "aponta a área de maior vulnerabilidade, onde o stress se manifesta na pessoa avaliada" (LIPP, 2017, p. 52), identificando a sintomatologia física e/ou psicológica ligada ao estresse.

Para além disso, convém analisar que a participação no Treinamento de Habilidades Sociais auxiliou no manejo do estresse de forma relevante pois houve redução considerável nos níveis de estresse entre os participantes, além de ser possível observar que a identificação do estresse e suas fases em universitários auxilia nas políticas estudantis de prevenção e promoção da saúde mental.

\section{REFERÊNCIAS BIBLIOGRÁFICAS}

BOAS, A. C. V. V.; SILVEIRA, F. F.; BOLSONI-SILVA, A. T. Descrição de efeitos de um procedimento de intervenção em grupo com universitários: um estudo piloto. Interação em Psicologia, Curitiba, v. 9, n. 2, p. 321-330, 2005.

BOLSONI-SILVA, A. T.; CARRARA, K. Habilidades Sociais e análise do comportamento: compatibilidades e dissensões conceitual-metodológicas. Belo Horizonte: Psicologia em Revista, v. 16, n. 2 agosto, 2010. Disponível em: $<$ http://pepsic.bvsalud.org/scielo.php?script=sci_arttext\&pid=S1677$11682010000200007>$ Acesso em: 27 de julho de 2019.

BORBA, C. S. de. Investigação dos sintomas de ansiedade social nos universitários. Manaus, 2018.

DEL PRETTE, A.; DEL PRETTE, Z. A. P. Habilidades Sociais: programas efetivas em grupo. São Paulo: Pearson Clinical Brasil, 2017. 
DEL PRETTE, Z. A. P.; DEL PRETTE, A. Inventário de habilidades sociais (IHSDelPrette): Manual de aplicação, apuração e interpretação. São Paulo: Casa do Psicólogo, 2001.

GAVASSO, M. S. B.; FERNANDES, J. S. G.; ANDRADE, M. S. Revisão sistemática de estudos sobre habilidades sociais: avaliação e treinamento. Ciências \& Cognição, 21(1), 2016.

LAMEU, J. do N; SALAZAR, T. L; SOUZA, W. F. Prevalência de sintomas de stress entre graduandos de uma universidade pública. Psic. da Ed., São Paulo, 42, $1^{\circ} \mathrm{sem}$. de 2016, pp. 13-22.

LIMA, C. A.; SOARES, A. B. Treinamento em Habilidades Sociais para universitários no contexto acadêmico: ganhos e potencialidades em situações consideradas difíceis. In: Del Prette, Z.A.P. et al. (Org.). Habilidades sociais diálogos e intercambios sobre pesquisa e prática. 1 ed. Nova Hamburgo: Sinopsys, v. 1, p. 22-43, 2016.

MONTEIRO, C. F. de. S.; FREITAS, J. F. de M.; RIBEIRO, A. A. P. Estresse no cotidiano acadêmico: o olhar dos alunos de enfermagem da universidade federal do Piauí. Teresina-PI: Escola Anna Nery, 2007.

MORETTO, L. A. Efeitos de uma intervenção em grupos em habilidades sociais na perspectiva da análise do comportamento. $91 \mathrm{f}$. Dissertação de Mestrado, Programa de Pós-graduação em Psicologia do Desenvolvimento e Aprendizagem, Universidade Estadual Paulista, Faculdade de Ciências, Bauru, 2017.

OLAZ, F. O. et al. Programa vivência versus programa instrucional de Habilidades Sociais: impacto sobre a autoeficácia de universitários. In: Z. A. P DEL PRETTE; DEL PRETTE, A. (Orgs). Habilidades Sociais: programas efetivas em grupo. São Paulo: Pearson Clinical Brasil, 2017.

ROCHA, J. F. Da. Efeitos de uma intervenção comportamental com treino de habilidades sociais para universitários com fobia social. $156 \mathrm{f}$. Dissertação de Mestrado, Programa de Pós-graduação em Psicologia do Desenvolvimento e Aprendizagem, Universidade Estadual Paulista, Faculdade de Ciências, Bauru, 2012.

ROSSETTI, M. O. et al. O inventário de sintomas de stress para adultos de lipp (ISSL) em servidores da polícia federal de São Paulo. Revista Brasileira de Terapias Cognitivas, v.4, n. 2, 2008.

SILVA G.; BONETTI, A.; GUTSTEIN, T. C. Efeitos de um programa de treinamento de habilidades sociais em universitários. In: Anas do II Congresso Internacional de Ciência, Tecnologia e Inovação, Umuarama, 2018.

SOARES, A. B. et al. O impacto dos comportamentos sociais acadêmicos nas habilidades sociais de estudantes. Gerais: Revista Interinstitucional de Psicologia, v. 10, n.1, junho, 2017. Disponível em 
$<$ http://pepsic.bvsalud.org/scielo.php?script=sci_arttext\&pid=S1983-

82202017000100008> Acessado em: 27 de julho de 2019.

STRAHAN, E. Y. The effects of social anxiety and social skills on academic

performance. Personality and Individual Differences, v. 34, n. 2, p. 347-366, 2003.

\section{Credenciais da/os autora/es}

NAZAR, Thaís Cristina Gutstein. Professora na Universidade Paranaense- UNIPAR, graduada em Psicologia (UNICENTRO), Mestre em Psicologia (UTP), Doutora em Educação (UFPR). E-mail: thaiscg@ prof.unipar.br

PERING, Amanda Caroline. Participante do Programa de Iniciação Científica- PIC, Campus de Francisco Beltrão, PR, Brasil. E-mail: amanda.pering@ hotmail.com.

GIROTTO, Déborah Alana. Participante do Programa de Iniciação Científica- PIC, Campus de Francisco Beltrão, PR, Brasil. E-mail: deborahagirotto@gmail.com.

KUCMANSKI, Tatiane. Participante do Programa de Iniciação Científica- PIC, Campus de Francisco Beltrão, PR, Brasil. E-mail: tatiane.kucmanski@edu.unipar.br.

Endereço para correspondência: Thaís Cristina Gutstein Nazar. V. Júlio Assis Cavalheiro, 2000 - Centro, Francisco Beltrão - PR, 85601-000. E-mail: thaiscg@prof.unipar.br

Como citar este artigo (Formato ABNT): Nazar, Thaís Cristina Gutstein; PERING, Amanda Caroline; GIROTTO, Déborah Alana; KUCMANSKI, Tatiane. Treinamento de habilidades sociais em universitários: um estudo acerca das variáveis estresse e habilidades sociais. Educação, Psicologia e Interfaces, v. 3, n.3, p. 190-204, 2019. DOI: https://doi.org/10.37444/issn-2594-5343.v4i1.210

Recebido: 14/10/2019.

Aceito: 30/11/2019.

Educação, Psicologia e Interfaces, Volume 4, Número 1, p. 190-204, Janeiro/Março, 2020.

ISSN: 2594-5343. DOI: https://doi.org/10.37444/issn-2594-5343.v4i1.210 